\title{
An in vitro biofilm model system maintaining a highly reproducible species and metabolic diversity approaching that of the human oral microbiome
}

Anna Edlund ${ }^{1,2+}$, Youngik Yang ${ }^{1 \dagger}$, Adam P Hall ${ }^{1}$, Lihong Guo ${ }^{2}$, Renate Lux ${ }^{2}$, Xuesong He${ }^{2}$, Karen E Nelson ${ }^{3}$, Kenneth H Nealson ${ }^{1,4}$, Shibu Yooseph ${ }^{1}$, Wenyuan Shi ${ }^{2}$ and Jeffrey S McLean ${ }^{1 *}$

\begin{abstract}
Background: Our knowledge of microbial diversity in the human oral cavity has vastly expanded during the last two decades of research. However, much of what is known about the behavior of oral species to date derives from pure culture approaches and the studies combining several cultivated species, which likely does not fully reflect their function in complex microbial communities. It has been shown in studies with a limited number of cultivated species that early oral biofilm development occurs in a successional manner and that continuous low pH can lead to an enrichment of aciduric species. Observations that in vitro grown plaque biofilm microcosms can maintain similar pH profiles in response to carbohydrate addition as plaque in vivo suggests a complex microbial community can be established in the laboratory. In light of this, our primary goal was to develop a robust in vitro biofilm-model system from a pooled saliva inoculum in order to study the stability, reproducibility, and development of the oral microbiome, and its dynamic response to environmental changes from the community to the molecular level.

Results: Comparative metagenomic analyses confirmed a high similarity of metabolic potential in biofilms to recently available oral metagenomes from healthy subjects as part of the Human Microbiome Project. A time-series metagenomic analysis of the taxonomic community composition in biofilms revealed that the proportions of major species at 3 hours of growth are maintained during 48 hours of biofilm development. By employing deep pyrosequencing of the $16 \mathrm{~S}$ rRNA gene to investigate this biofilm model with regards to bacterial taxonomic diversity, we show a high reproducibility of the taxonomic carriage and proportions between: 1) individual biofilm samples; 2) biofilm batches grown at different dates; 3) DNA extraction techniques and 4) research laboratories.

Conclusions: Our study demonstrates that we now have the capability to grow stable oral microbial in vitro biofilms containing more than one hundred operational taxonomic units (OTU) which represent $60-80 \%$ of the original inoculum OTU richness. Previously uncultivated Human Oral Taxa (HOT) were identified in the biofilms and contributed to approximately one-third of the totally captured $16 \mathrm{~S}$ rRNA gene diversity. To our knowledge, this represents the highest oral bacterial diversity reported for an in vitro model system so far. This robust model will help investigate currently uncultivated species and the known virulence properties for many oral pathogens not solely restricted to pure culture systems, but within multi-species biofilms.
\end{abstract}

Keywords: In vitro model, Biofilm, Oral microbiome, Saliva, Streptococcus, Lactobacillus, Uncultivated bacteria

\footnotetext{
*Correspondence: jmclean@jcvi.org

†Equal contributors

${ }^{1}$ Microbial and Environmental Genomics, J. Craig Venter Institute, 10355

Science Center Drive, CA 92121 San Diego, USA

Full list of author information is available at the end of the article
} 


\section{Background}

The human oral cavity harbors a highly diverse and unique microbiome, which exists in a continuously changing environment where $\mathrm{pH}$, organic carbon and oxygen levels fluctuate on a hundred-fold or even a thousand-fold scale within minutes $[1,2]$. From the first discovery that dental plaque $\mathrm{pH}$ will decrease after sucrose consumption and then return to baseline values $[3,4]$, the oral microbial community has been a highly studied system not only because of its health-related significance but also for demonstrating interactions between species and functional analysis of multi-species communities in general [5-7]. Difficulties in studying this complex and structurally heterogeneous environment are multifaceted, and include problems related to the species variability of human subjects, continuous access to samples over time, small sample sizes and complicated ethical issues. This has led to the development of both synthetic consortia biofilm model systems and in vitro microcosm plaque from the human natural oral flora by using growth systems, including chemostats [8], the constant-depth film fermentor (CDFF) [9], saliva-conditioned flow cells $[10,11]$ and artificial mouths [12]. Results from these studies show that the multispecies biofilms, containing a hand full of bacterial species, are functionally reproducible with heterogeneous structures and $\mathrm{pH}$ behaviors consistent with those of natural plaque $[13,14]$. As investigators started to understand that the microbial diversity within the oral microbiome is highly important in both health and disease they began to explore multiple species interactions by using mixedspecies models consisting of up to 10 defined species. This led to the synthesis of the 'ecological plaque hypothesis', which proposes that selection of cariogenic bacteria is directly coupled to alterations in the environment that shifts the balance of the community [15]. According to this hypothesis, if the $\mathrm{pH}$ remains below the critical $\mathrm{pH}$ (value of 5.5) for demineralization for extended time periods after a carbohydrate pulse, a shift in the bacterial populations to more cariogenic organisms that are acidproducing (acidogenic) and acid-tolerant (aciduric) occurs $[16,17]$. Another important aspect of this hypothesis is that any species with relevant traits can contribute to the disease process $[15,18]$. This was also supported by multiple findings that bacterial species, other than well-known pathogens (for example, Streptococcus mutans) are present in caries-active sites $[19,20]$. Also, a recent study shows that one can detect several low-pH active species present in a healthy plaque, which may be responsible for the onset of caries disease [21].

In order to fill in the knowledge gaps in species diversity for these complex communities, the Human Microbiome Project (HMP) [22,23], the Human Oral Microbiome Database (HOMD) [24] and the CORE database [25] have been established. The major goal of the HMP was to characterize bacterial communities that are associated with several different body sites as well as generate a catalog of reference genomes from species derived from human hosts [26]. The HOMD specifically contains information on the prokaryotic species present in the human oral cavity and has the capacity to link sequence data with phenotypic, phylogenetic, clinical and bibliographic information. The curated version of HOMD, published by Dewhirst and colleagues in 2010 contains approximately 619 validated taxa with 1,178 total taxa identified, of which $24 \%$ are named, $8 \%$ are cultivated but unnamed and $68 \%$ represented uncultivated phylotypes [27]. Human oral taxa are defined as sharing 98.5\% similarity in $16 \mathrm{~S}$ rRNA (henceforth abbreviated as 16S) gene sequences [27]. A major hurdle to understanding the oral microbiome is the unknown contribution of the very large uncultivated fraction of the existing bacterial diversity. In fact, the greatest number of the 'most wanted taxa' (that is, those that have been seen by $16 \mathrm{~S}$ sequencing but remain uncultivated) targeted for whole genome sequencing in the human body reside in the oral cavity [28,29]. The identity of these oral phylotypes can only be linked to possible functions by using techniques such as nucleic acid-based stable isotope probing (SIP) [21] or singlecell genomics based sequencing approaches [30,31]. Moreover, due to the high taxonomic variability of the oral microbiome between study subjects it is extremely difficult to track species and strains temporally and spatially [23]. Also, small sample sizes that are dictated by availability of volunteers and costs, limit the statistical power needed to detect small, but important differences among communities. Hence, to gain a deeper ecological understanding of the processes that are involved in the gradual succession of healthy oral microbiomes to diseaseassociated microbiomes, it is important to continue the development of oral microbial model systems where experiments can be conducted in a controlled environment. The advantages with such systems are many as they provide novel opportunities to study microbial community ecology with systems biology perspectives by using global omics experimental tools (metagenomics, metatranscriptomics, metabolomics). A model system also allows for generating biological replicates and contributes to the analyses of large samples that are needed to obtain reliable spatial and temporal dynamics data of bacterial populations within a community.

In this study, our aim was to develop a mixedcommunity biofilm model system comprising the highest possible cultivable bacterial diversity representative of the resident saliva-derived microbiome responsible for plaque formation in the human oral cavity. We used a recently developed growth medium (SHI medium) that previously was shown to support growth of a highly diverse microbiome and that also had a high coverage of species 
found in the original inoculum saliva samples obtained from healthy adults [32]. To evaluate the reproducibility of this in vitro model system and to address its overall metabolic potential we applied both conventional community fingerprinting, denaturing gradient gel electrophoresis (DGGE), and next-generation sequencing. The broader taxonomic reproducibility of biofilms growing in two different research laboratories was tested by comparing $16 \mathrm{~S}$ gene profiles from DGGE. To obtain a broader understanding of the whole biofilm community diversity, deep sequencing of $16 \mathrm{~S}$ genes via 454-pyrosequencing and whole genome shotgun (WGS) sequencing on the Illumina HiSeq platform was performed. To our knowledge, the model we have developed represents the highest oral bacterial diversity that has been reported for an in vitro system thus far. This model can be used to gain a deeper understanding of molecular mechanisms that underlie the evolution of healthy oral microbiomes into disease-associated microbiomes where cariogenic groups such as mutans streptococci and Lactobaccilli become more abundant $[7,19,33,34]$. This model will also aid in the understanding of oral microbial communities by facilitating discovery and functional characterization of known, as well as uncultivated bacteria, within a mixed-species system that is approaching the diversity of in vivo conditions. Importantly, it will allow systematic investigation of species, specific genes/domains, gene products and metabolic pathways that define the synergistic and competitive contributions to health and disease in the complex oral microbiome.

\section{Methods}

\section{Saliva collection}

Saliva samples were collected from six healthy subjects, age 25 to 35 years as described by Tian and colleagues [32]. Consents from study subjects, including consent to participate in the study and consent to publish findings from saliva samples were obtained. Subjects were asked to refrain from any food or drink $2 \mathrm{hrs}$ before donating saliva and to spit directly into the saliva collection tube; $5 \mathrm{ml}$ saliva was collected from each person. Ethical approval of all protocols related to saliva collection and experimental research was confirmed by the Institutional Review Board (IRB) (University of California Los Angeles IRB \#11-002483). Saliva samples were pooled together and centrifuged at 2,600 g for 10 minutes to spin down large debris and eukaryotic cells. The supernatant was referred to as pooled saliva and used throughout this study. Cell-free saliva was also used for coating wells prior to growing the biofilms as described below.

\section{Culturing and growth of saliva-derived biofilms using SHI medium}

To assess the diversity and the reproducibility of the saliva inoculum pool and our highly diverse in vitro grown biofilms we used several incubation approaches and molecular techniques. An overview of the applied conditions is presented in Table 1. Prior to saliva inoculation into SHI medium, (fully described in Tian et al. [32]) within a sterile 24-well plate, $200 \mu \mathrm{l}$ of saliva supernatant was added to each well. This pre-coating of wells allows attached pellicle growth. The plates were then incubated at $37^{\circ} \mathrm{C}$ with the lid open for $1 \mathrm{hr}$ to dry the saliva coating. Plates were then sterilized under UV light for $1 \mathrm{hr}$ before $10 \mu \mathrm{l}$ of pooled saliva was inoculated into a pre-coated well containing $10 \mu \mathrm{l}$ of sucrose $(0.5 \%), 990 \mu \mathrm{l}$ SHI medium. Plates were incubated at $37^{\circ} \mathrm{C}$ under anaerobic conditions for $16 \mathrm{hrs}$ to allow biofilm formation. The biofilms were carefully washed twice with a buffered chemically defined medium (CDM), which is fully described in [21]. After the washing steps, biofilms were starved (that is, incubated without carbon source) in fresh CDM medium $(\mathrm{pH} 7)$ for $2 \mathrm{hrs}$ in $37^{\circ} \mathrm{C}$ and incubated under anaerobic conditions (Table 1). After starvation the biofilms were harvested for DNA extraction and 16S gene analyses by using 454-pyrosequencing as explained below. For the temporal analyses of bacterial taxa by using a metagenomics approach, biofilm samples were harvested at the

Table 1 in vitro biofilm analyses parameters used in this study to test reproducibility

\begin{tabular}{|c|c|c|c|}
\hline Goal & $\begin{array}{l}\text { Samples and number of } \\
\text { replicate wells }\end{array}$ & $\begin{array}{l}\text { Incubation conditions prior to DNA } \\
\text { extraction }\end{array}$ & $\begin{array}{l}\text { Community profile } \\
\text { technique }\end{array}$ \\
\hline \multirow[t]{5}{*}{ Address batch and well reproducibility } & Batch $1 \times 1$ & Step I: 16 hrs growth in SHI medium & 16S-454 pyrosequencing \\
\hline & Batch $2 \times 2$ & & \\
\hline & Batch $3 \times 3$ & & \\
\hline & Saliva $\times 3$ & Step II: 2 hrs starvation in CDM & \\
\hline & & No incubation & \\
\hline $\begin{array}{l}\text { Address reproducibility between research } \\
\text { laboratories }\end{array}$ & $\begin{array}{l}\text { With sucrose } \times 2 \text { without } \\
\text { sucrose } \times 2\end{array}$ & $\begin{array}{l}16 \text { hrs growth in SHI medium with or } \\
\text { without sucrose }\end{array}$ & DGGE \\
\hline $\begin{array}{l}\text { Address temporal taxonomic diversity during } \\
\text { biofilm development }\end{array}$ & $\begin{array}{l}\text { Time course } \\
\text { (hrs) }=3,6,9,12,16,48\end{array}$ & 48 hrs growth in SHI medium & $\begin{array}{l}\text { WGS metagenomes } \\
\text { Illumina HiSeq }\end{array}$ \\
\hline
\end{tabular}

CDM, chemically defined medium; DGGE, denaturing gradient gel electrophoresis; WGS, whole genome shotgun. 
following time points when growing in SHI medium as explained above: 3, 6, 9, 12, 16, and 48 hrs (Table 1). Two replicate biofilm sample wells were harvested at $6 \mathrm{hrs}$ of growth. Note that these biofilms were grown for $48 \mathrm{hrs}$ in total and not starved in minimal medium as compared to the samples that were devoted to 454-pyrosequencing.

\section{Glucose and pH monitoring of biofilm growth medium}

After the 2-hr period of starvation, $1 \mathrm{ml}$ of $0.5 \%$ glucose in fresh CDM ( $\mathrm{pH} 7$ ) was added to each biofilm well. Glucose levels were then measured in the biofilm growth medium by using the glucose-specific TRUE2go blood monitoring system (CVS Pharmacy, Inc., Woonsocket, RI, USA). A 3- $\mu$ l sample was withdrawn from a glucosedesignated sample well throughout the biofilm incubation. This sample was added to a sterile plastic surface inside the anaerobic chamber prior to applying the test strip, which was then mounted onto the electronic glucosemeter reader. Three replicate samples were analyzed at incubation time points: zero, 2, 4, 5, 6 hrs. The lower limit for glucose detection of the TRUE2go blood monitoring device is $20 \mathrm{mg} / \mathrm{dl}$, which was reached after $5 \mathrm{hrs}$ of incubation. Biofilm-growth medium $\mathrm{pH}$ was monitored in near real-time within replicate $\mathrm{pH}$-designated incubation wells and measured by combining $\mathrm{pH}$ Laboratory Electrodes (EW-05990-65, Cole-Parmer, Court Vernon Hills, IL, USA) with a wireless sensor network platform consisting of a pH transmitter (UWPH-2-NEMA, OMEGA, Stamford, CT, USA) and a $\mathrm{pH}$ receiver (UWTC-REC1, OMEGA). $\mathrm{pH}$ was monitored in the same fashion in the biofilm growth wells that were incubated for $48 \mathrm{hrs}$ in SHI medium and subjected to metagenomics analyses. $\mathrm{pH}$ measurements were monitored and downloaded onto a computer using TC central software for UWTC (OMEGA). Real-time pH was recorded for 48 hrs every 30 seconds within each growth well.

\section{DNA extraction and processing of pyrosequencing data}

DNA was isolated as described in [21] using the DNeasy Blood and Tissue Kit (Qiagen Inc., Maryland, USA) and eluted in a final volume of $200 \mu \mathrm{l}$ water. Biofilms representing the batch-2 samples were a part of a stable isotope probing (SIP) time-series study (unpublished) in which a series of samples were subjected to ${ }^{13} \mathrm{C}$-labelled glucose amendments in the CDM buffer as described in McLean et al. 2012 [21]. However, the batch-2 samples described in this study were not fed labeled ${ }^{13} \mathrm{C}$-glucose, as they served as controls and were collected immediately (time point zero hours of incubation). The DNA from the SIP-treated biofilm replicate samples (batch-2 samples) was separated by centrifugation against a cesium chloride $(\mathrm{CsCl})$ density-gradient [21]. The sample processing of these particular samples was conducted as follows: (1) entire DNA was extracted from each sample and loaded into the gradient solution; (2) gradient formation was achieved by centrifugation at $265,000 \times \mathrm{g}$ for $66 \mathrm{hrs}$ in a Beckman VTi65 rotor (Beckman Coulter, Inc., Fullerton, CA, USA); (3) fractions were collected $(400 \mu \mathrm{l})$ and the DNA was isolated using a YM-100 Microcon column (Millipore, Billerica, MA, USA); (4) columns were washed four times with TE buffer and purified DNA was eluted into $50-\mu \mathrm{l}$ volumes. Biofilm samples representing batch 1 and batch 3 were not subjected to ultracentrifugation. After genomic DNA extraction and quantification, all samples were prepared for $16 \mathrm{~S}$ amplification and titanium-based 454pyrosequencing at the J. Craig Venter Institute (JCVI) Joint Technology Center (JTC). Genomic DNA sample concentrations were normalized to 2 to $6 \mathrm{ng} / \mu \mathrm{l}$. The V3 to $\mathrm{V} 5$ region of $16 \mathrm{~S}$ genes was amplified according to the previously developed protocol available at http://www. nature.com/nature/journal/v486/n7402/extref/nature11209s1.pdf [23]. Using each sample's individual barcodes, the 454 sequence data were deconvolved into the respective samples. After trimming the bar codes, low-quality and short sequences $(<100 \mathrm{bp})$ were removed by using the JCVI $16 \mathrm{~S}$ pipeline. Subsequently, the remaining filtered reads were aligned against the SILVA database of $16 \mathrm{~S}$ to verify that the reads were indeed $16 \mathrm{~S}$. The Chimera Slayer tool was used to filter out potentially chimeric reads [32].

\section{PCR-DGGE analysis}

Reproducibility of $16 \mathrm{~S}$ gene diversity was tested by two different research laboratories, JCVI, San Diego, CA, USA and the School of Dentistry, University California Los Angeles (UCLA), CA, USA. Both research laboratories carried out saliva inoculation from the same saliva pool into SHI medium prepared independently at each laboratory. Samples were incubated and washed at the different locations as described above. Genomic DNA extractions, PCR amplification and DGGE analyses were carried out at the UCLA laboratory. Amplification of bacterial $16 \mathrm{~S}$ genes and DGGE analysis was carried out as described in a previously published protocol [32]. The universal primer set Bac1 and Bac2 [35] was used to amplify an approximately 300-bp internal $16 \mathrm{~S}$ fragment of the $16 \mathrm{~S}$ gene.

\section{Biofilm and saliva operational taxonomic unit (OTU) diversity in pyrosequencing libraries}

To compare OTU diversity between saliva and biofilm samples, the following analysis steps were conducted using the MOTHUR software [36]: (1) quality filtered fragment reads were assigned to OTUs in $97 \%$ sequence identity level; (2) distances of samples in datasets were calculated in terms of OTU profile; (3) Yue and Clayton metrics was applied, which measures structure dissimilarities between communities [37]; (4) the obtained Yue and Clayton matrix was used to calculate and visualize 
sample similarities using correspondence analysis (CA) [38] in the ADE-4 software [39].

\section{Identification and phylogenetic analysis of $16 \mathrm{~S}$ genes}

To identify previously defined oral bacterial taxa in the biofilm and saliva samples, a reference alignment was initially created by downloading $16 \mathrm{~S}$ RefSeq Extended Version 1.1 from Human Oral Microbiome Database (HOMD) [24], which consists of 1,647 sequences that includes named, unnamed and uncultivated phylotypes. By using this reference sequence set we generated 1,642 non-redundant sequences by using cd-hit-est [40] with $100 \%$ sequence identity and $95 \%$ alignment coverage for the shorter sequence. The 1,642 sequences were aligned by cmalign in the Infernal package [41]. A phylogenetic tree was generated with RAxML [42] using this alignment. By using blastn [43], our sequence reads from the saliva and biofilm samples were aligned to the HOMD reference sequences. Matches at $97 \%$ sequence identity cutoff and 95\% sequence coverage were considered. Match counts for saliva and biofilm samples were scaled in base-10 log. Reference tree and the counts were visualized by using the online interactive tree of life (iTol) software [44]. In the figure, color ranges were shown at phylum level. Bar charts next to leaf labels show log scale match counts for saliva and in vitro biofilm samples, respectively (Figure 2). A bubble chart was generated based on the base-10 log transformed match counts to show sample similarities for human oral taxon (HOT) designations (named, unnamed and uncultivated phylotypes) in biofilm samples batch 2, well 1 to well 2, and batch 3 , well 1 to well 3 .

\section{Metagenomic analyses of biofilms}

WGS sequencing was performed on total DNA that was extracted from biofilms growing in individual growth wells at 3, 6, 9, 12, 16, and 48 hrs of growth in SHI medium. Replicate libraries were prepared from two biofilms representing 6 hrs of growth. WGS sequences (fragment and paired-end reads) were obtained from the Illumina HiSeq platform, quality trimmed and filtered using CLC workbench software v. 6.0.1 (CLCbio, Aahus, Denmark). The following CLC-parameters were applied during paired read sequence trimming and quality control: quality score setting: NCBI/Sanger or Illumina Pipeline 1.8 and later, minimum distance: 180 , maximum distance: 250. The trimmed reads were subjected to sequence assembly by using the CLC workbench (CLCbio). ORF calling and annotations were performed on the contigs obtained from the CLC workbench according to the JCVI prokaryotic metagenomics pipeline [45]. A summary of metagenomic read numbers, contig numbers and identified ORFs for each sample is presented in Additional file 1:
Table S1. Metagenome annotations were uploaded for comparative analyses with metagenomes from the HMP on METAREP [46]. HMP assembly annotations, available via the HMP through the JCVI-supported METAREP (http://www.jcvi.org/hmp-metarep) representing supragingival plaque, keratinized gingiva, mid vagina, posterior fornix and anterior nares body sites were used for hierarchical cluster analysis together with biofilm samples representing 12 and $16 \mathrm{hrs}$ of growth. Cluster analyses were performed using the Multiple Experiment Viewer $(\mathrm{MeV})$ (version. 4.8.1) (http://www.tm4.org/mev.html) the average linkage setting and Pearson correlation as distance measure. Bacterial community compositions were profiled for all time points using the metagenomic read-based analysis tool MetaPhlAn (version 1.7.7) $[23,47]$. This computational tool relies on clade-specific marker genes from 3,000 reference genomes and performs estimations of organism relative abundance in terms of numbers of cells rather than fraction of reads.

\section{Results and discussion}

\section{Meeting the challenges with oral in vitro model systems}

The goal of this study was to develop and validate with deep sequencing, a novel robust in vitro model system representative of the naturally complex oral microbiome. In previous studies of biodiverse model biofilm systems a major approach has been to construct synthetic plaquelike consortia represented by a handful of plaque species [18,48-50]. Other methods represent inoculating and growing bacteria from natural saliva in plaque microcosms such as the artificial mouth [12,51-54]. The latter studies of natural saliva focus solely on physiological responses and do not consider taxonomic diversity at $16 \mathrm{~S}$ gene level. Studies that derive from less diverse synthetic plaque communities show intriguing examples of how certain oral bacteria form advantageous partnerships that are necessary for growth of other species and that these partnerships sometimes are also observed in vivo [55-57]. Each model system has strengths, limitations and difficulties. However, they all represent better study models than the uncontrollable environment of the mouth. A major challenge when using any oral model system is to maintain a representative diversity of the indigenous oral microbiome. This was specifically addressed in a previous study by Tian and colleagues [32], who developed a growth medium (SHI medium) that supported a remarkably high number of oral taxa in vitro from a small number of human saliva samples which were inoculated and grown as biofilms. Here we employed this medium with the goal to select for the highest possible diversity representative of the oral cavity, high reproducibility and stability at the species level in this in vitro biofilm model. 


\section{Pooling saliva samples from different sampling subjects prior to inoculation}

To meet the above stated goals it was necessary to pool saliva samples from several humans to acquire enough biomass for the startup of multiple in vitro sample growth wells in parallel. This enabled us to study numerous replicate samples simultaneously by using multiple analyses approaches such as 454-pyrosequencing of $16 \mathrm{~S}$ genes, measurement of $\mathrm{pH}$ and sugar levels during growth and future comparative studies on the saliva pool, such as metabolomics and metatranscriptomics. Another important aspect of the pooling of saliva samples was that it allowed us to domesticate previously uncultivable community members, such as those belonging to the candidate phylum TM7 and the genus Porphyromonas [58]. Several of these community members would most likely have been missed if we had studied saliva from one single person due to the high taxonomic variability between humans [33]. However, a limitation of using a pool of saliva samples deriving from several individuals as inoculum in the in vitro model system is that the native community integrity is lost as the samples are mixed together. Most likely, each person who participated in this study harbored a unique saliva microbiome, which may not be accurately reflected from a community diversity perspective here. Clearly, in future studies it is important to address how a single person's microbiome evolves taxonomically and metabolically over time in our in vitro model and to what extent species within a native community accomplish certain functions only in their native setting as compared to when they are mixed with other community members from other individuals.

\section{Moderating the sugar concentration for the highest diversity}

Initially, through our deep sequencing experiments we sought to confirm the most appropriate concentration of additional sucrose needed in the SHI medium to best represent the saliva-derived oral community that our previous DGGE results showed more qualitatively [32]. The responses to two carbon source concentrations added to the SHI medium $(0.1 \%$ and $0.5 \%$ sucrose $)$ and a control with no sucrose were tested by sequencing $16 \mathrm{~S}$ genes from the resulting biofilms grown in vitro. We found that $0.5 \%$ sucrose was able to maintain the saliva-derived diversity in biofilms most similar to the saliva inoculum in terms of the genera observed (see Additional file 2: Figure S1). In contrast, the no-sucrose biofilm was less diverse and was dominated by a single Streptococcus species, S. mitis. The $0.1 \%$ sucrose-amended sample was similar to the one grown in the presence of $0.5 \%$ sucrose but had a higher proportion of subgingival community members, such as Porphyromonas. This confirmed that $0.5 \%$ sucrose was the better choice for our model and that the taxonomic diversity responds rapidly to environmental changes.

\section{Physiological responses to carbohydrate pulse are similar to in vivo plaque}

After establishing the growth conditions, we sought to confirm that the general physiological response of a plaque biofilm is maintained in vitro (that is, similar to the Stephan curve) $[3,4]$. This particular response has been acknowledged for decades as the classic Stephan curve where oral acidogenic bacteria rapidly metabolize fermentable carbohydrates producing acidic byproducts and then the $\mathrm{pH}$ returns to baseline $[3,4]$. When we initiated biofilm incubation with $0.5 \%$ glucose in fresh CDM the $\mathrm{pH}$ started to drop instantly (see Additional file 3: Figure $\mathrm{S} 2$ ). $\mathrm{pH}$ was neutral in the beginning of the incubation and decreased to 4.5 after 4 hours. At 6 hours it had reached its lowest level (4.2) and then it started to recover. Glucose concentrations followed the same falling pattern and after 5 hours were below the detection limit $(20 \mathrm{mg} / \mathrm{dl})$ showing a rapid turnover of this substrate by bacteria in the biofilms (see Additional file 3: Figure S2). Rapid glucose utilization and conversion to lactate and acetate was also shown in this CDM for $S$. mutans and fresh plaque samples derived from children using nuclear magnetic resonance techniques $[21,59]$. These results confirm that our in vitro model system shows a similar physiological response to a glucose challenge as previously described for dental plaque and in vitro-tested salivary sediments [60,61]. Overall, the response of this model biofilm is consistent with dental plaque containing species capable of lowering and also raising the $\mathrm{pH}$.

\section{Reproducibility between research laboratories}

After optimizing the community towards a higher diversity, 16S gene amplification and DGGE analyses were performed from biofilm samples that shared the same pool of saliva but were grown by two different research laboratories (UCLA School of Dentistry, and JCVI) to test technical reproducibility (see Additional file 4: Figure S3). Although the saliva inoculum was shared, completely independent media reagents and growth procedures were carried out in the respective labs. The resulting replicate gel images were aligned and $16 \mathrm{~S}$ band patterns were compared for samples that had been incubated with or without $0.5 \%$ sucrose, showing that despite the variations between labs, the resulting community composition was highly reproducible. The majority of the DGGE bands showed similar fluorescence intensity across replicates and only one major band was missing in the replicate samples deriving from the JCVI laboratory (see Additional file 4: Figure S3). 


\section{Reproducibility across batches (alpha diversity) and between wells within a batch (beta diversity)}

To evaluate the reproducibility between batches and between growth wells within a batch for our model system in-depth, we analyzed 454-pyrosequencing data obtained from biofilms cultivated on different dates (batches 1, 2, and 3) and grown in replicate growth wells from the same freshly thawed saliva pool (Table 1). Included were two biofilm samples (batch 2, well 1 and 2) that had been subjected to 66 hours of DNA centrifugation, which served as a control in a parallel SIP experiment (unpublished). The biofilm samples batches 1, 2, and 3 were all grown and processed on different days to assess the reproducibility of batches at different time points; replicate growth wells from batches 2 and 3 were compared to address the variation between biofilm growth wells. Similarities in OTU diversity between replicates from all biofilm batches and from saliva inoculum samples were estimated using CA (Figure 1). In CA, the saliva samples were similar and clustered together but separately from the biofilm samples. The biofilm libraries that derived from batch 2 clustered separately from biofilm samples representing batches 1 and 3 that formed a separate cluster. The difference between batch 2 and the other biofilm samples was most likely due to the fact that the batch 2 samples were centrifuged over an extensive period of time in a $\mathrm{CsCl}$ gradient, which according to many SIP studies will separate high GC DNA from low GC and thus likely resulted in a skewed $16 \mathrm{~S}$ profile. Regardless of this difference however, these centrifuged samples were highly similar to each other, and the community profiles for replicate biofilm samples were highly reproducible, which supports their potential to serve as replicate samples for experiments in which a particular treatment is compared.

\section{S gene diversity in pooled saliva and biofilm samples}

In order to assess the bacterial phylogenetic diversity in saliva and biofilm samples at a higher resolution, reference sequences from the HOMD were used to taxonomically classify $16 \mathrm{~S}$ genes from this study (Figure 2; Additional file 5: Table S2). Matching HOT designations and their log-transformed abundance values were aligned on the outside of an in-house constructed HOMD-phylogenetic tree (see Methods) at their corresponding branch tips. Within the HOMD-classified 16S genes that were obtained from this study more strain diversity (that is, sequences showing $>98.5 \%$ sequence similarity) was observed but is not included here. In total, 6 phyla and 41 genera of bacteria were identified in the different samples (singletons included) (Figure 2). These corresponded to 264 HOT designations of which 131 also could be detected in one or several biofilm samples. Several of the dominant genera (for example, Streptococcus, Veillonella, Prevotella) were equally abundant in samples grown at different time points and in samples grown in different incubation wells, showing that the biofilms grown in vitro are highly reproducible (Figure 3 ). This was also shown by the low standard deviations of HOT abundance values

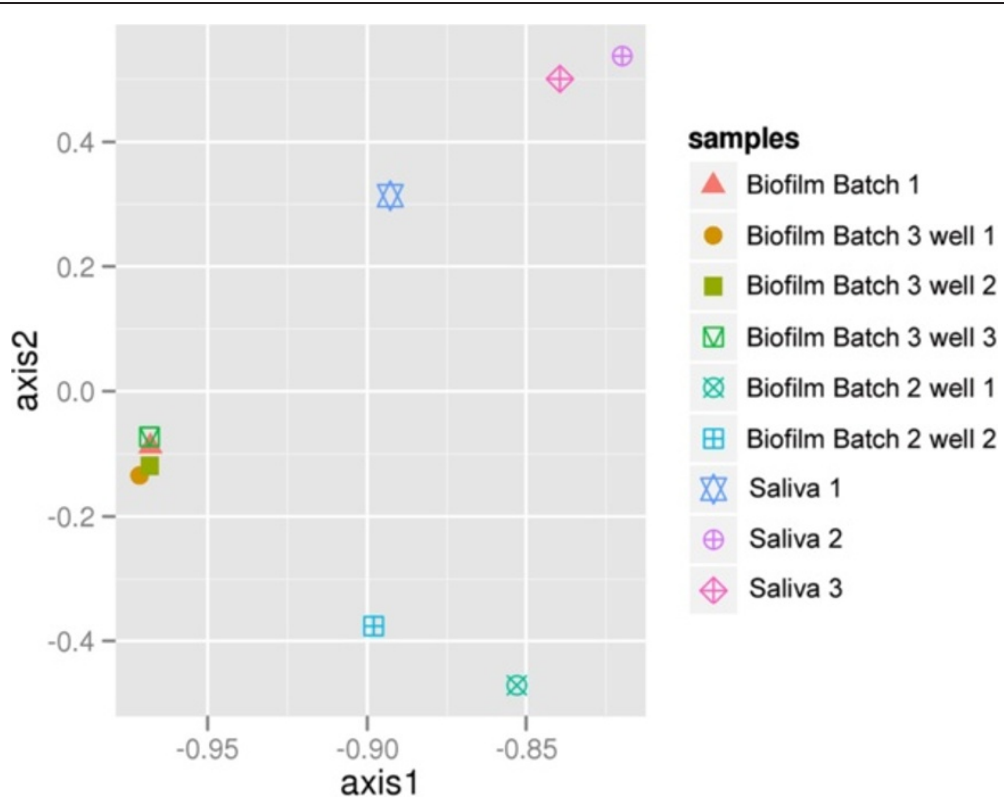

Figure 1 Correspondence analysis showing reproducibility and $16 \mathrm{~S}$ profile similarities within biofilm and saliva samples. Axis 1 explains $47 \%$ of the variation in the dataset; axis 2 explains 19\% of the variation. Replicate biofilm samples representing batches 1 and 3 cluster closely together whereas batch-2 biofilms that derive from an SIP experiment cluster more distantly along the first ordination axis. Saliva-derived replicates (1 to 3) also show similar $16 \mathrm{~S}$ diversity. 


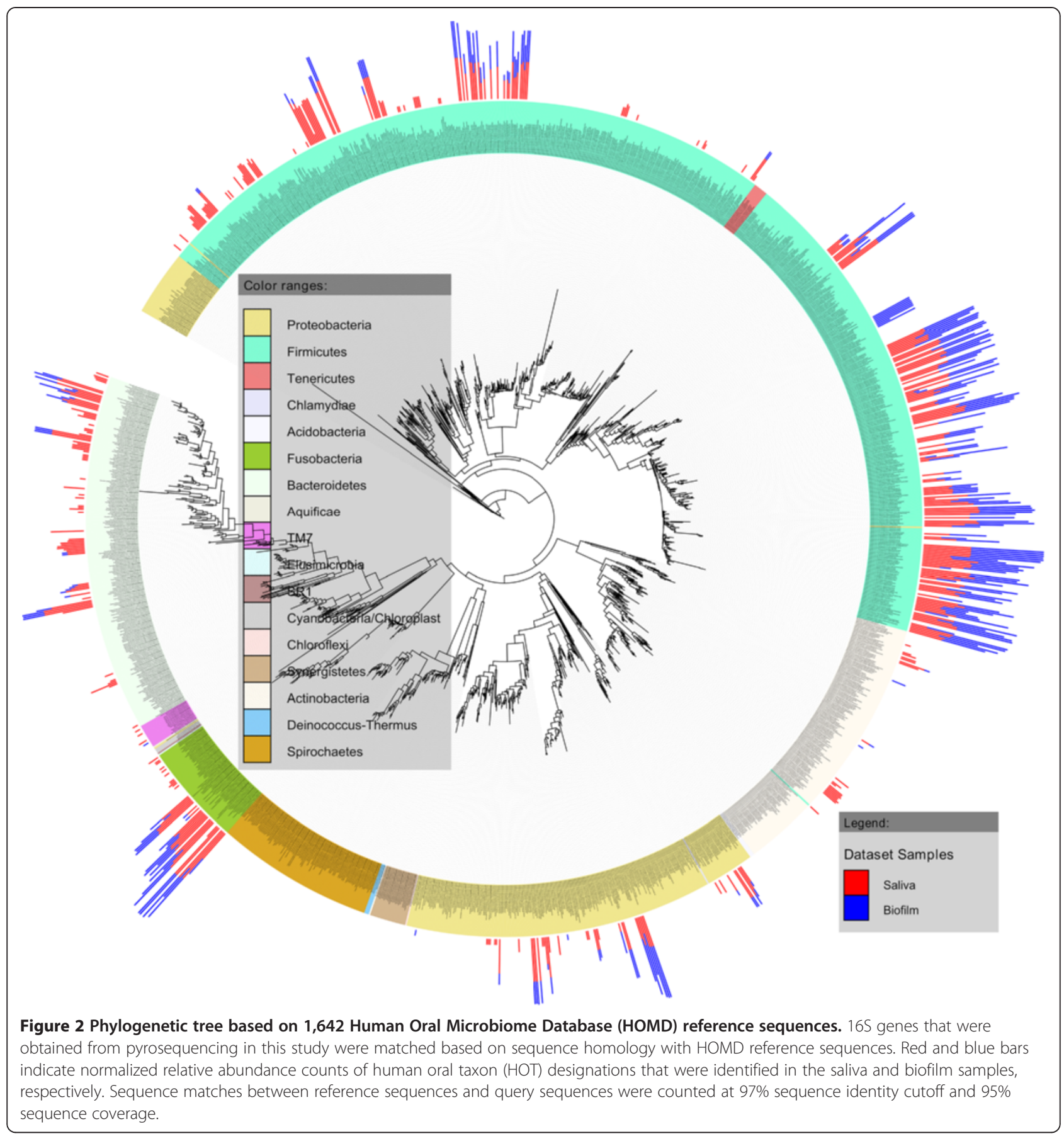

between replicate libraries, which ranged between $0.1 \%$ and $8 \%$ across replicate samples. Of particular note, 51 uncultivated HOT designations belonging to the Streptococcus, Granulicatella, Haemophilus, Lactobacillus, Parvimonas, Peptostreptococcus, Prevotella, Solobacterium, Fusobacterium, Veillonella, Porphyromonas and TM7 G-2 genera could be identified in the biofilm growth wells (Figure 3B). Identification of the most abundant genera in saliva and biofilm samples was done by removing genera that encompassed HOT-designations that contributed with two hundred or fewer $16 \mathrm{~S}$ genes counts, corresponding to $<0.3 \%$ of total $16 \mathrm{~S}$ gene abundance (Table 2). Two genera (Streptococcus and Veillonella) were detected in biofilms when using the latter criteria while nine were identified when including the rare community members (those that were represented with $\leq 20016$ S gene counts). These results show that most of the diversity in the in vitro biofilms could be attributed to the Streptococcus and Veillonella genera, which is in line with previous findings of healthy oral microbiomes [33]. 


\section{Streptococcus}

Members belonging to the genus Streptococcus are predominant bacterial species of human saliva and supragingival biofilms $[23,62,63]$, which also were observed for the biofilm in vitro model system in this study. The most dominant HOT designations belonged to S. vestibularis, S. salivarus, S. mitis, S. parasanguinis and a variety of understudied Streptococcus sp. strains (Figure 3). S. vestibularis HOT-021 contributed approximately $40 \%$ to the total $16 \mathrm{~S}$ abundance in all replicate biofilm samples, whereas $S$. salivarus (HOT-755) and the uncultivated phylotype Streptococcus sp (HOT-C65) both contributed 10\% each. $S$. vestibualris is a normal inhabitant of the oral cavity and has rarely been associated with human disease except in a few cases of infectious endocarditis, early neonatal sepsis and bacteremia in cancer patients [64]. Also, S. vestibularis was previously shown to produce only low levels of caries in rats when compared to other
Streptococcus species (for example, S. salivarus) [65]. The impacts on oral human health of $S$. salivarus span a broad range from being strongly cariogenic $[66,67]$ to caries-protective by hydrolyzing urea to ammonia [68-70]. S. parasanguinis strains HOT-721 and HOT711 were also abundant in the in vitro biofilms but contributed only half of the $16 \mathrm{~S}$ sequence read-abundance when compared to $S$. salivarus and Streptococcus sp. HOT-C65. The ecological role of S. parasanguinis in oral health is also poorly understood but due to its capacity to ferment multiple carbohydrates to lactate and other organic acids it is considered to be a moderately acid-tolerant organism and a cariogenic species $[71,72]$. Previous studies show that it has been significantly associated with both caries in young children and healthy oral flora $[73,74]$. Our in vitro biofilm model supports growth of several S. parasanguinis strains in concert and can be used to test these relationships further.

Table 2 Numbers of human oral taxa (HOT) within the most dominant genera in saliva and biofilm samples

\begin{tabular}{|c|c|c|c|c|c|c|}
\hline \multirow{4}{*}{$\begin{array}{l}\text { Bacterial phyla (bold) } \\
\text { and genera (italics) }\end{array}$} & \multirow{4}{*}{$\begin{array}{c}\begin{array}{c}\text { Number of } \\
\text { HOT identified }\end{array} \\
\text { Saliva }^{a}\end{array}$} & \multirow{4}{*}{$\begin{array}{c}\text { Number of HOT } \\
\text { identified in vitro } \\
\text { Biofilm }^{\mathrm{a}}\end{array}$} & \multirow{3}{*}{\multicolumn{2}{|c|}{$\begin{array}{c}\text { Number uncultivated } \\
\text { Phylotypes (P) } \\
\text { HOMD }^{\mathrm{a}}\end{array}$}} & \multirow{3}{*}{\multicolumn{2}{|c|}{$\begin{array}{c}\text { Number uncultivated } \\
\text { Phylotypes }(\mathrm{P}) \\
\text { HOMD }^{\mathrm{b}}\end{array}$}} \\
\hline & & & & & & \\
\hline & & & & & & \\
\hline & & & Saliva & Biofilm & Saliva & Biofilm \\
\hline \multicolumn{7}{|l|}{ Firmicutes } \\
\hline Streptococcus & $25(58)$ & $38(58)$ & 6 & 11 & 25 & 25 \\
\hline Veillonella & $3(9)$ & $2(9)$ & 1 & 1 & 5 & 5 \\
\hline Parvimonas & $4(6)$ & $0(2)$ & 1 & ND & 1 & 1 \\
\hline Mogibacterium & $4(5)$ & $0(5)$ & ND & ND & ND & ND \\
\hline Gemella & $3(3)$ & $3(3)$ & ND & ND & ND & ND \\
\hline Peptostreptococcus & $3(3)$ & $0(3)$ & 3 & ND & ND & ND \\
\hline Granulicatella & $1(2)$ & $1(2)$ & ND & ND & 2 & 2 \\
\hline Klebsiella & $0(2)$ & $2(2)$ & ND & ND & ND & ND \\
\hline Lactobacillus & $0(0)$ & $1(2)$ & ND & ND & ND & 1 \\
\hline \multicolumn{7}{|l|}{ Bacteroidetes } \\
\hline Prevotella & $3(38)$ & $0(11)$ & 1 & ND & 3 & 3 \\
\hline Porphyromonas & $1(8)$ & $0(6)$ & ND & ND & 4 & 4 \\
\hline \multicolumn{7}{|l|}{ Fusobacteria } \\
\hline Fusobacterium & $4(12)$ & $2(11)$ & 2 & ND & 5 & 5 \\
\hline \multicolumn{7}{|l|}{ Proteobacteria } \\
\hline Neisseria & $5(11)$ & $0(7)$ & ND & ND & ND & ND \\
\hline Campylobacter & $1(5)$ & $0(3)$ & 1 & ND & ND & ND \\
\hline \multicolumn{7}{|l|}{ TM7: } \\
\hline TM7 (G-1) & $0(2)$ & $0(0)$ & ND & ND & 2 & ND \\
\hline TM7 (G-2) & $0(0)$ & $0(1)$ & ND & ND & ND & 1 \\
\hline TM7 (G-3) & $0(1)$ & $0(0)$ & ND & ND & 1 & ND \\
\hline
\end{tabular}

HOT designations were defined according to the Human Oral Microbiome Database (HOMD) classification scheme. (), Total numbers of HOT, including singletons, are presented inside brackets. ${ }^{a}$ Uncultivated phylotypes were identified based on the HOMD classification. The numbers of phylotypes representing HOT designations with $>20016 \mathrm{~S}$ gene counts (corresponding to $>0.3 \%$ of total $16 \mathrm{~S}$ counts) are presented in these columns. ${ }^{\mathrm{b}} \mathrm{All}$ HOT designations (including those that were represented by 1 to 200 copies of $16 S$ gene reads). ND, no uncultivated HOMD representative was detected. 


\section{Lactobacilli}

Members belonging to the Lactobacillus genus are found in low abundance in supragingival samples from healthy subjects and are thought to be late colonizers in microbial succession [23]. They are commonly observed in advanced caries and are isolated on low pH agar [75-77]. In the in vitro biofilms two Lactobacillus species (L. fermentum HOT-608 and Lactobacillus sp. HOT-A89) could be identified at a low abundance (average $0.8 \%$ ), which is relatively close to the abundance of L. fermentum (0.2\%) observed in the clone libraries used to generate the HOMD. This represents an opportunity to challenge the model and track the increase in these cariogenic species, simulating a transition from a healthy community to a more disease-like state.

\section{Veillonella atypica/Veillonella dispar/Veillonella parvula/ Veillonella sp.}

The presence of these understudied species in our biofilm model gives us future opportunities to learn more about the role of Veillonella in oral community succession and caries. In previous studies of Veillonella its ecological role has been unclear and laboratory studies show that effects of $\mathrm{pH}$ on its growth can be mixed $[78,79]$. It has also been suggested that the presence of Veillonella could possibly be used as a predictor of future caries in caries-free children and that it has a close and complex relationship to the pathogen $S$. mutans, which also was detected in this study $[20,80]$.

\section{Fusobacterium}

Bacterial community members belonging to the Fusobacterium genus contributed approximately $10 \%$ to the total $16 \mathrm{~S}$ gene diversity in the biofilm communities. Like most of the other oral community members they are known to be associated both with the normal human oral flora and also with certain oral diseases [81]. Their ability to grow in many different habitats can be explained by their broad metabolic versatility as they can obtain energy from fermentation of a broad range of simple sugars and amino acids, free or in the form of peptides [81]. Three strains representing the invasive host pathogen F. nucleatum were identified here as well as a strain representative of F. peridonticum $[82,83]$.

Several previously identified oral pathogens were observed at notably low $16 \mathrm{~S}$ gene abundance in all samples (for example, S. mutans HOT-686, Rothia mucilaginosa HOT-681, Abiotrophia defectiva HOT-389, Atopobium rimae HOT-750, Porphyromonas catoniae HOT-283, Prevotella melaninogenical HOT-469) (Figure 2) indicating the pathogenic potential present in samples derived from healthy oral subjects. A representative of the elusive candidate Phylum TM7 [G-2] that was previously identified in both healthy human subjects and in subjects with periodontal disease and other inflammatory mucosal infections [84-86] was also present at a low abundance in a biofilm sample (Figure 3).

\section{Diversity indices in 454-sequencing libraries}

Although classification-based methods have the benefit of being associated with a reference taxonomy, these methods cannot account for the diversity that is missing from the reference databases. Therefore, we applied an OTU-based approach to complement the above classification approach. These results show that OTU richness was lower in biofilm samples compared to saliva samples, ranging from 65 OTUs in the batch-2 well-1 sample to 156 OTUs in the batch-3 and batch-2 samples (Table 3). In line with these results, the Shannon entropy $(\mathrm{H})$ index was also slightly higher in the saliva-derived samples (4.39 to 4.72) compared to the biofilm samples where $H$ varied from 4.11 to 4.23 . Although it is clear that the biofilms at this selected time point do not fully capture every species found in a saliva sample, the in vitro biofilms in this study

Table 3 Diversity and count estimates of $16 \mathrm{~S}$ genes in pyrosequencing libraries after sequence trimming

\begin{tabular}{|c|c|c|c|c|}
\hline Sample & $\begin{array}{l}\text { Number of raw } 16 \mathrm{~S} \text { rRNA } \\
\text { fragment reads }\end{array}$ & $\begin{array}{l}\text { Number of OTUs after } \\
\text { pre-cluster analyses }\end{array}$ & Shannon entropy & Shannon evenness \\
\hline Biofilm batch 1 & 6011 & 132 & 3.7436 & 0.7620 \\
\hline Biofilm batch 2 well $1^{\text {a }}$ & 5731 & 107 & 3.6971 & 0.7960 \\
\hline Biofilm batch 2 well $2^{a}$ & 8538 & 158 & 4.1868 & 0.8200 \\
\hline Biofilm batch 3 well 1 & 4835 & 154 & 4.1622 & 0.8284 \\
\hline Biofilm batch 3 well 2 & 5166 & 146 & 4.1082 & 0.8289 \\
\hline Biofilm batch 3 well 3 & 4778 & 148 & 4.2334 & 0.8683 \\
\hline Saliva 1 & 6956 & 208 & 4.7209 & 0.8544 \\
\hline Saliva 2 & 6885 & 243 & 4.7209 & 0.8544 \\
\hline Saliva 3 & 3799 & 179 & 4.5234 & 0.8828 \\
\hline
\end{tabular}

Biofilm batches 1, 2 and 3 correspond to replicate biofilm samples grown at different time points. The biofilm batch-2 library was generated from stable isotope probing experiments (see Methods). ${ }^{a}$ Wells 1, 2 and 3 correspond to replicate technical samples collected from different sample wells. ${ }^{b}$ Numbers of operational taxonomical units (OTUs) after precluster-analyses using the SILVA reference alignment and the MOTHUR software. 
contain the highest $16 \mathrm{~S}$ diversity identified so far within an in vitro oral model system.

\section{Metabolic reproducibility and temporal taxonomic shifts as shown by WGS}

Using a WGS approach to further investigate the in vitro biofilm community, we confirmed that the type and proportions of metabolic pathways present in our in vitro biofilm model, here represented by two annotated metagenomes, were in strong agreement with those recently reported for supragingival plaque, keratinized gingiva (gum tissue closest to the teeth) and saliva samples in the HMP studies of 242 healthy human subjects (Figure 4) $[23,33]$. This was shown in the Kyoto Encyclopedia of Genes and Genomes (KEGG) pathway and enzyme classification comparison-analyses where major pathways (for example, secondary metabolite biosynthesis, glycan biosynthesis and metabolism, metabolism of cofactors, vitamins, terpenoids, polyketides, lipids, amino acids, energy, nucleotides and translation) were more similar for the oral sites compared to anterior nares (external position of nostrils), mid vagina and posterior fornix (area behind lower portion of uterus) body sites. Comparing the enzyme classification of the body sites at lower levels further supports the overall functional similarities with supragingival plaque (Figure 4; Additional file 6: Figure S4 and Additional file 7: Figure S5). These findings are in line with the HMP study of healthy
Western subjects which revealed that there is large variation in carriage of taxa (community structure) but stable metabolic pathways exist across individuals for many body sites including supragingival plaque [23]. Here the 16S datasets and our WGS data show that our in vitro biofilm model has a different but stable taxonomic diversity, which harbors a highly similar metabolic potential representative of the human oral cavity. Taken together, both the results of this study and the HMP study suggests that some variation in the relative proportions of taxa in a model system such as this may be tolerated, as the functional capabilities (carbohydrate utilization and $\mathrm{pH}$ buffering) of the community may remain similarly stable and allow us to gain some fundamental understanding as to what is happening in vivo.

\section{Biofilm development as studied using metagenomics}

The relative abundance of bacterial species shifted in biofilms over a time period of 48 hours of growth in sucrosesupplemented SHI medium (Figure 5). Initially, at $3 \mathrm{hrs}$ of growth, $S$. parasanguinis represented the most dominant community member, contributing approximately $25 \%$ to the total read abundance. S. cristatus and S. salivarus were also dominant members at this stage, each contributing approximately $15 \%$ to the total read abundance. As pH decreased, the abundance of S. parasanguinis and S. cristatus decreased until reaching 16 hrs. At 48 hrs Lactobacillus fermentum had increased significantly in relative abundance

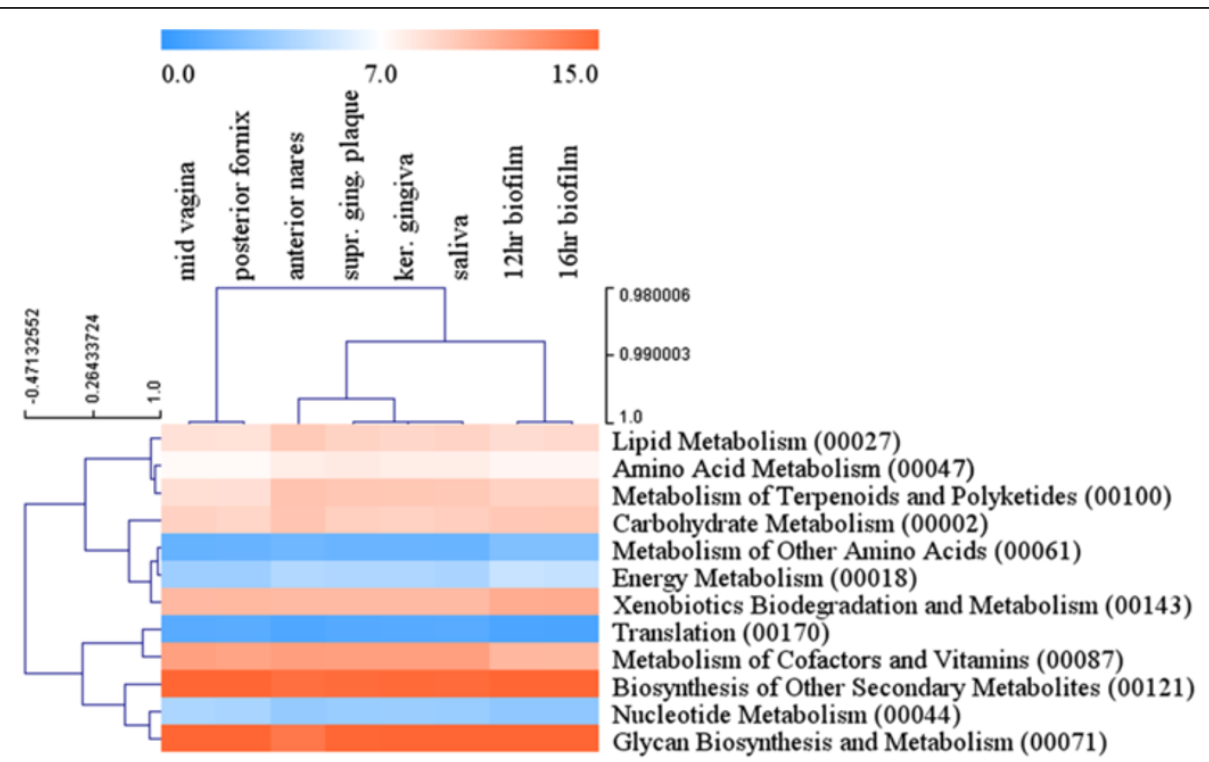

Figure 4 Metabolic profile comparisons of Human Microbiome Project (HMP) oral metagenomes, other HMP-body sites and the in vitro biofilm metagenomes. The METAREP tool was used to compare Kyoto Encyclopedia of Genes and Genomes (KEGG) super pathways representing the 12- and 16-hrs-old in vitro biofilms from this study with HMP-oral metagenomes representing supragingiva, keratinized gingiva and saliva samples from healthy subjects. These oral metagenomes were also compared to HMP metagenomes from other body sites, that is, anterior nares (external position of nostrils), mid vagina and posterior fornix (area behind lower portion of uterus) by using hierarchical cluster analyses of ORF abundance data for each sample. Colored bar in the top indicates relative abundance in percentage of annotated ORFs that fall within each KEGG super pathway (blue, approximately $0 \%$; white, approximately $6 \%$; red, approximately $16 \%$ ). 


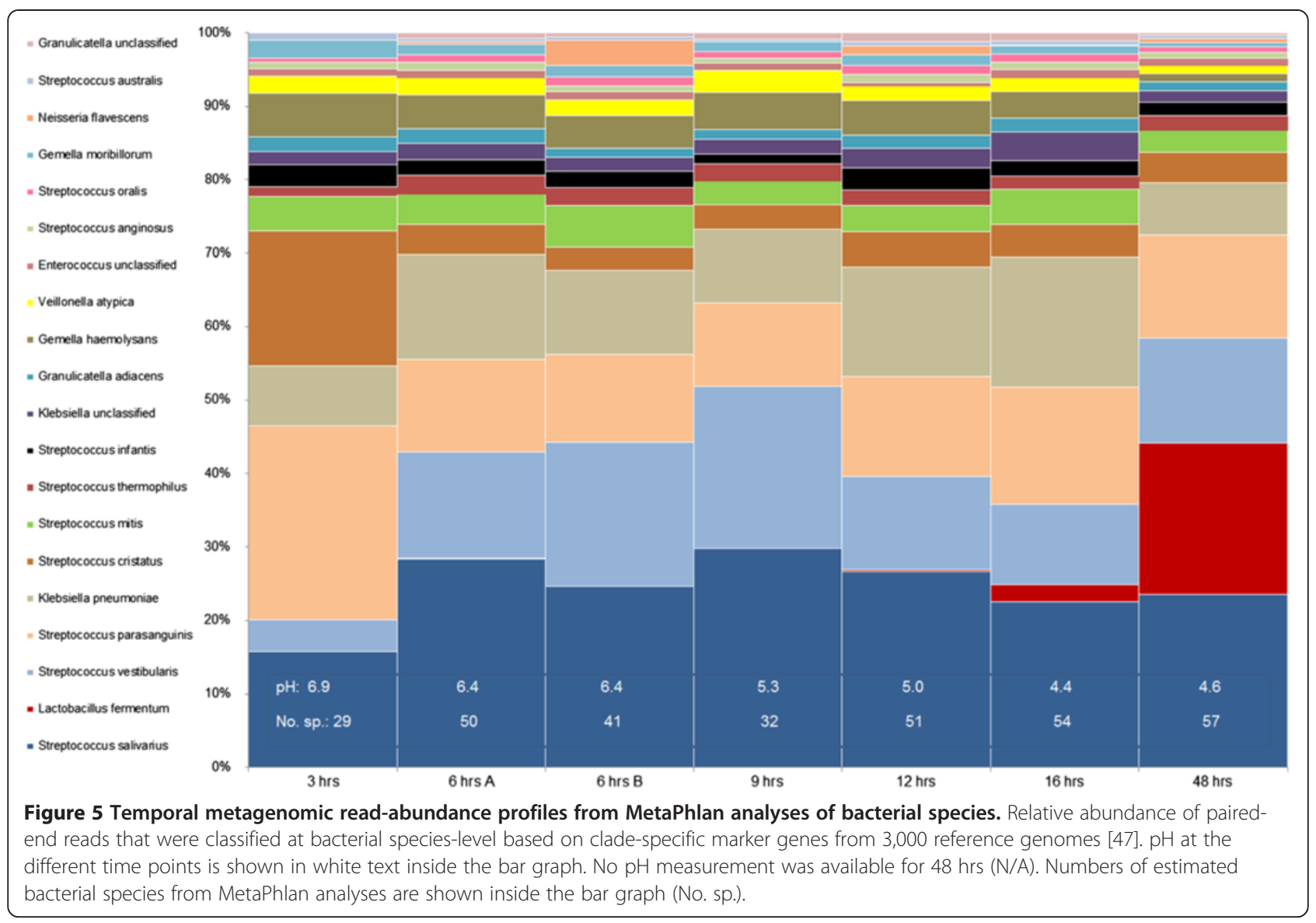

whereas Klebsiella pneumonia had decreased from circa 20 to $10 \%$ between 16 and 48 hrs of biofilm development. $\mathrm{pH}$, which was measured over a time period of 48 hrs, reached its lowest levels of $\mathrm{pH} 4.4$ at $16 \mathrm{hrs}$ when the abundance of the acidogenic and cariogenic species Lactobacillus fermentum started to increase (Figure 5). It is likely that inhibition of metabolism, due to low $\mathrm{pH}$ and possibly carbohydrate limitation, starts to impact growth of some community members between 12 and $16 \mathrm{hrs}$ and this leads to a shift in the community structure. Moreover, the number of bacterial species that was identified using the MetaPhlan tool was the highest after 48 hrs of growth, showing that this species diversity was still increasing over time (Figure 5). Growth development and bacterial activity are important aspects that need to be addressed in future studies by sampling with higher temporal resolution in the early stages of growth and coupling this to measurements of live biomass and possibly transcription changes.

Taken together with the $16 \mathrm{~S}$ gene sequencing results showing that L. fermentum was a rare species in the early stages of in vitro growth and that $L$. fermentum is considered a late colonizer of oral plaque [20] as the $\mathrm{pH}$ decreases, it is likely that the in vitro biofilm community was at an intermediate state of succession at the time point of $16 \mathrm{~S}$ gene analysis (16 hrs). With this information, we can possibly modulate the community to resemble an early or later stage of development. Likewise, it would be interesting to test how the biofilm develops and differs if a saliva pool of diseased subjects is used. Its usefulness in human health research could span a wide range, as saliva pools with different origin could be collected and inoculated based on the tested hypotheses (for example, inoculum can represent saliva from diseased human subjects or healthy subjects with highly different microbiomes). Overall, these results reflect that this model system maintains a high number of species that can be used to study both the healthy ( $\mathrm{pH}$ balancing) and acid-tolerant species associated with disease.

\section{Conclusions}

The principal challenge in most sub-fields of microbiology still relates to the microbial cultivation barrier. In the human oral cavity the proportions of uncultured species are lower (approximately 60\%) than in other environments [87-89]; however, the missing species are a significant impediment to the study of human health. The use of an in vitro model system with a highly complex bacterial 
diversity that also supports growth of uncultivated oral species is highly desirable, as it can be manipulated and studied in a controlled environment. To our knowledge, the model we developed here is the first validated system at the species and gene level that fulfills these criteria and that can be readily used to target changes in taxa, regulation of metabolic pathways and signaling molecules, using next-generation sequencing and omics methodologies. For the 131 HOT designations that were identified in the in vitro biofilms 48 fully sequenced genomes are available through HOMD, showing that we now have the ability to perform in-depth genome analyses at the community level. Longitudinal studies of an in vitro model system such as this will generate deeper fundamental knowledge of the mechanisms regulating bacterial taxonomic diversity and community functions in both health and disease. Specifically, such a model system will help facilitate experimental approaches that seek answers to questions concerning caries-related diseases and how oral pathogens can be eradicated. We hope that it will be used in future research as a tool to understand and combat the development of oral disease.

\section{Availability of supporting data}

The datasets supporting the results of this article are included within the article (and its additional files).

\section{Additional files}

Additional file 1: Table S1. Summary of whole genome shotgun (WGS) data for metagenomics analyses of in vitro biofilms at 3, 6, 9, 12, 16 and 48 hrs of growth.

Additional file 2: Figure S1. Correspondence analyses of bacterial community structures based on 165 gene analyses; levels of sucrose that served as a carbon substrate during the first $16 \mathrm{hrs}$ of biofilm growth in $\mathrm{SHI}$ medium. High sugar and low sugar levels correspond to 0.5 and $0.1 \%$ sucrose, respectively. The inoculum sample corresponds to the pooled saliva sample. 165 rRNA community profiles in the high-sugar biofilms were more similar to the natural saliva samples.

Additional file 3: Figure S2. Glucose and pH responses in biofilm growth wells during growth in minimal chemically defined medium (CDM). (A) Glucose concentration in replicate biofilm samples after spiking samples with $0.5 \%$ glucose at time point zero hrs. After glucose concentrations were below $20 \mathrm{mg} / \mathrm{dl}$ ( $6 \mathrm{hrs}$ ) they could no longer be detected (dashed line) and were considered as $0 \mathrm{mg} / \mathrm{dl}$. (B) Replicate $\mathrm{pH}$ profiles of biofilm samples after glucose spiking. $\mathrm{pH}$ levels decreased during the first six hours of incubation in parallel with glucose consumption. pH recovery could be observed after 6 hrs of glucose spiking.

Additional file 4: Figure S3. Polymerase chain reaction and denaturing gradient gel electrophoresis (DGGE) from two different research laboratories. DGGE gel images showing reproducibility of bacterial $16 \mathrm{~S}$ gene profiles representing two replicate DNA extractions (left and right panels) from the saliva-derived inoculum cultured in SHI medium with (w/ sucrose) and without sucrose (w/o sucrose) at two different research laboratories (JCVI and UCLA). DGGE band patterns were similar within and between research laboratories and only one DGGE band was missing in replicate samples as indicated by arrows.
Additional file 5: Table S2. $16 \mathrm{~S}$ rRNA read counts in saliva and in vitro biofilm samples and their corresponding genome match in the Human Oral Microbiome Database (HOMD).

Additional file 6: Figure S4. Hierarchical cluster analyses of Kyoto Encyclopedia of Genes and Genomes (KEGG) pathways representing 12and 16-hrs-old in vitro biofilms in this study and Human Microbiome Project (HMP) metagenomes corresponding to post fornix, anterior nares (Nares), buccal mucosa, subgingiva, keratinized gingiva, saliva, supragingiva and keratinized gingiva samples from healthy subjects. Note that saliva metagenomes were derived from the HMP and not from this study. Colored bar in the top indicates relative abundance in percentage of annotated ORFs that fall within each KEGG pathway (blue,

approximately $0 \%$; white, approximately $10 \%$; red approximately $20 \%$ ). The 20 most abundant KEGG pathway hits are presented here. A total of 147 hits were identified in all metagenomes using METAREP.

Additional file 7: Figure S5. Hierarchical cluster analyses of METAREP enzyme classifications (Level 4). Metagenomes representing 12- and 16hrs-old in vitro biofilms in this study and Human Microbiome Project (HMP) metagenomes corresponding to post fornix, anterior nares (Nares), buccal mucosa, subgingiva, keratinized gingiva, saliva, supragingiva and keratinized gingiva samples from healthy subjects were included here. Note that saliva metagenomes were derived from the HMP and not from this study. Colored bar in the top indicates relative abundance in percentage of annotated ORFs that fall within each Kyoto Encyclopedia of Genes and Genomes (KEGG) pathway (blue, approximately 0\%; white, approximately $0.01 \%$; red, approximately $0.5 \%$ ). The 29 most abundant enzyme hits are presented here. A total of 1591 enzymes were identified in all metagenomes at METAREP enzyme level 4.

\section{Abbreviations}

16S: $16 S$ rDNA gene that encode 16S ribosomal RNA; 16S RefSeq Extended Version 1.1: A dataset that contains 1,647 165 rRNA gene sequences representing all currently named and unnamed oral taxa as well as taxa that have not yet been assigned with a taxon identity; 454-pyrosequencing: A method of DNA sequencing based on 'sequencing by synthesis' which was licensed to 454 Life Sciences (Banford, CT). It involves taking a single strand of DNA and then synthesizing its complementary strand enzymatically. The pyrosequencing method is based on finding the activity of the DNA polymerase; Bp: Base pairs; CA: Correspondence analysis is a multivariate statistical technique that applies to categorical data. It provides a means of displaying or summarizing a set of data in two-dimensional graphical form; cd-hit-est: A computer program designed to quickly group nucleotide sequences into clusters that meet a user-defined similarity threshold; CDM: A chemically defined medium that simulates saliva medium for oral bacterial species; DGGE: Denaturing gradient gel electrophoresis is a form of electrophoresis which uses a chemical gradient to denature the samples as it moves across an acrylamide gel. It is applied to separate nucleic acids based on fragment size and nucleotide content; HMP: The National Institute of Health-funded Human Microbiome Project had the goal to characterize microbial communities found at multiple human body sites and to look for correlations between changes in microbial and human health; HOMD: The Human Oral Microbiome Database provides comprehensive information on the approximately 700 prokaryote species that are present in the human oral cavity; HOT: A human oral taxon is defined with a unique ID number in HOMD that is linked to its unique 165 rRNA gene phylotype for which phenotypic phylogenetic, genomic, clinical and bibliographic information is available; iTo: The Interactive Tree of Life software is an online tool for the display and manipulation of phylogenetic trees; JCVI: (Joint Craig Venter Institute); KEGG: Kyoto Encyclopedia of Genes and Genomes; OTU: Operational taxonomic unit species distinction in microbiology. A 97\% rDNA sequence similarity threshold for classifying bacteria within the same or different OTUs was used in this study; PCR: Polymerase chain reaction; RAxM: A statistical method for maximum likelihood phylogeny estimation; SHI medium: A previously developed blood-based growth medium that supports growth of a diversity of oral bacteria; SILVA: A database that provides comprehensive quality checked and regularly updated datasets of aligned small and large subunits ribosomal RNA (rRNA) sequences for all three domains of life; SIP: Stable isotope probing is a technique that identifies active microorganisms that assimilate particular carbon substrates and nutrients into cellular biomass. It is an important technology for 
assigning metabolic functions to microbial communities. Following the incubation of an environmental sample with stable-isotope labeled compounds extracted nucleic acid is subjected to density gradient ultracentrifugation and gradient fractionation to separate nucleic acids of differing densities; UCLA: University of California Los Angeles; WGS: Whole genome shotgun sequencing is a sequencing technology where DNA is broken up randomly into numerous small segments which are sequenced to obtained reads.

\section{Competing interests}

Dr. W Shi is a part time Chief Science Officer of C3 Jian Inc., which has licensed technologies from UC Regents that could be indirectly related to this research project. The other authors declare no competing interests.

\section{Authors' contributions}

$A E, R L, X H, K E N, K H N, S Y, W S$, and JSM designed the experiments, AE, APH, $L G$, and $X H$ collected and processed the samples, AE, YY, SY, and JSM analyzed the data and AE and JSM drafted the manuscript. All authors helped edit the manuscript. All authors read and approved the final manuscript.

\section{Acknowledgements}

This work was supported by grants from the National Institutes of Health NIDCR 1R01DE020102 to WS, RL and JSM as well as NIGMS 1R01GM095373 to JSM and a T90 NIH award to AE.

\section{Author details}

${ }^{1}$ Microbial and Environmental Genomics, J. Craig Venter Institute, 10355 Science Center Drive, CA 92121 San Diego, USA. 'CLA School of Dentistry, 10833 Le Conte Avenue, CHS Box 951668, Los Angeles, CA, 90095, USA. ${ }^{3}$ Department of Human Genomic Medicine, J. Craig Venter Institute, 9704 Medical Center Drive, Rockville, MD 20850 USA. ${ }^{4}$ Department of Earth Sciences, USC, ZHS 117, Los Angeles, CA 90089 USA.

Received: 17 July 2013 Accepted: 17 September 2013 Published: 2 October 2013

\section{References}

1. Takahashi N, Yamada T: Effects of $\mathrm{pH}$ on the glucose and lactate metabolisms by the washed cells of Actinomyces naeslundii under anaerobic and aerobic conditions. Oral Microbiol Immunol 1999, 14:60-65.

2. Lemos JA, Abranches J, Burne RA: Responses of cariogenic streptococci to environmental stresses. Curr Issues Mol Biol 2005, 7:95-107.

3. Stephan RM, Hemmens ES: Studies of changes in $\mathrm{pH}$ produced by pure cultures of oral micro-organisms; effects of varying the microbic cell concentration; comparison of different micro-organisms and different substrates; some effects of mixing certain micro-organisms. J Dent Res 1947, 26:15-41.

4. Stephan RM, Hemmens E: pH studies on oral micro-organisms. J Dent Res 1946, 25:172.

5. Foster JS, Palmer RJ Jr, Kolenbrander PE: Human oral cavity as a model for the study of genome-genome interactions. Biol Bull 2003, 204:200-204

6. Kolenbrander PE, Jakubovics NS, Chalmers NI, Palmer RJ Jr: Human Oral Multi-Species Biofilms: bacterial Communities in Health and Disease. In The Biofilm Mode of Life: Mechanisms and Adaptations. Edited by Staffan Kjelleberg KG, Michael G, Contributor Staffan Kjelleberg MG. Norwich, UK: Horizon Scientific Press; 2007:175-194.

7. Kleinberg I: A mixed-bacteriae ecological approach to understanding the role of the oral bacteria in dental caries causation: An alternative to Streptococcus mutans and the specific-plaque hypothesis. Critical Reviews in Oral Biology \& Medicine 2002, 13:108-125.

8. Bradshaw DJ, McKee AS, Marsh PD: Effects of carbohydrate pulses and pH on population shifts within oral microbial communities in vitro. J Dent Res 1989, 68:1298-1302.

9. Kinniment SL, Wimpenny JW, Adams D, Marsh PD: Development of a steady-state oral microbial biofilm community using the constant-depth film fermenter. Microbiology 1996, 142(Pt 3):631-638.

10. Cook GS, Costerton JW, Lamont RJ: Biofilm formation by Porphyromonas gingivalis and Streptococcus gordonii. J Periodontal Res 1998, 33:323-327.
11. Foster JS, Kolenbrander PE: Development of a multispecies oral bacterial community in a saliva-conditioned flow cell. Appl Environ Microbiol 2004 70:4340-4348

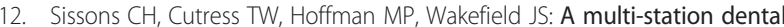
plaque microcosm (artificial mouth) for the study of plaque growth, metabolism, pH, and mineralization. J Dent Res 1991, 70:1409-1416.

13. Marsh P: Dental plaque as a microbial biofilm. Caries Res 2004, 38:204-211.

14. Sissons $\mathrm{CH}$ : Artificial dental plaque biofilm model systems. Adv Dent Res 1997, 11:110-126.

15. Marsh PD: The significance of maintaining the stability of the natural microflora of the mouth. Br Dent J 1991, 171:174-177.

16. Marsh PD: Microbiology of caries and periodontal diseases. Fogorv Sz 1997, 90:29-36.

17. Hodgson RJ, Lynch RJ, Watson GK, Labarbe R, Treloar R, Allison C: A continuous culture biofilm model of cariogenic responses. J Appl Microbiol 2001, 90:440-448.

18. Bradshaw DJ, Marsh PD: Analysis of $\mathrm{pH}$-driven disruption of oral microbial communities in vitro. Caries Res 1998, 32:456-462.

19. Aas JA, Griffen AL, Dardis SR, Lee AM, Olsen I, Dewhirst FE, Leys EJ, Paster $B J$ : Bacteria of dental caries in primary and permanent teeth in children and young adults. J Clin Microbiol 2008, 46:1407-1417.

20. Gross EL, Beall CJ, Kutsch SR, Firestone ND, Leys EJ, Griffen AL: Beyond Streptococcus mutans: dental caries onset linked to multiple species by 16S rRNA community analysis. PLoS One 2012, 7:e47722.

21. McLean JS, Fansler SJ, Majors PD, McAteer K, Allen LZ, Shirtliff ME, Lux R, Shi W: Identifying low $\mathrm{pH}$ active and lactate-utilizing taxa within oral microbiome communities from healthy children using stable isotope probing techniques. PLoS One 2012, 7:e32219.

22. Turnbaugh PJ, Ley RE, Hamady M, Fraser-Liggett CM, Knight R, Gordon J: The human microbiome project. Nature 2007, 449:804-810.

23. Consortium HMP: A framework for human microbiome research. Nature 2012, 486:215-221.

24. Chen T, Yu WH, Izard J, Baranova OV, Lakshmanan A, Dewhirst FE: The Human Oral Microbiome Database: a web accessible resource for investigating oral microbe taxonomic and genomic information. Database (Oxford) 2010, 2010:baq013.

25. Griffen AL, Beall CJ, Firestone ND, Gross EL, Difranco JM, Hardman JH, Vriesendorp B, Faust RA, Janies DA, Leys EJ: CORE: a phylogeneticallycurated 16S rDNA database of the core oral microbiome. PLOS One 2011, 6:e19051.

26. Human Microbiome Jumpstart Reference Strains Consortium, Nelson KE, Weinstock GM, Highlander SK, Worley KC, Creasy HH, Wortman JR, Rusch DB, Mitreva M, Sodergren E, Chinwalla AT, Feldgarden M, Gevers D, Haas BJ, Madupu R, Ward DV, Birren BW, Gibbs RA, Methe B, Petrosino JF, Strausberg RL, Sutton GG, White OR, Wilson RK, Durkin S, Giglio MG, Gujja S, Howarth C, Kodira CD, Kyrpides N, Mehta T, et al: A catalog of reference genomes from the human microbiome. Science 2010, 328:994-999.

27. Dewhirst FE, Chen T, Izard J, Paster BJ, Tanner AC, Yu WH, Lakshmanan A, Wade WG: The human oral microbiome. J Bacteriol 2010, 192:5002-5017.

28. Fodor AA, DeSantis TZ, Wylie KM, Badger JH, Ye Y, Hepburn T, Hu P, Sodergren E, Liolios K, Huot-Creasy H, Birren BW, Earl AM: The "most wanted" taxa from the human microbiome for whole genome sequencing. PLoS One 2012, 7:e41294

29. Campbell JH, O'Donoghue P, Campbell AG, Schwientek P, Sczyrba A, Woyke T, Söll D, Podar M: UGA is an additional glycine codon in uncultured SR1 bacteria from the human microbiota. Proc Natl Acad Sci USA 2013, 110:5540-5545.

30. Lasken RS: Genomic sequencing of uncultured microorganisms from single cells. Nat Rev Microbiol 2012, 10:631-640.

31. Marcy Y, Ouverney C, Bik EM, Losekann T, Ivanova N, Martin HG, Szeto E, Platt D, Hugenholtz P, Relman DA, Quake SR: Dissecting biological "dark matter" with single-cell genetic analysis of rare and uncultivated TM7 microbes from the human mouth. Proc Natl Acad Sci USA 2007, 104:11889-11894.

32. Tian Y, He X, Torralba M, Yooseph S, Nelson KE, Lux R, McLean JS, Yu G, Shi W: Using DGGE profiling to develop a novel culture medium suitable for oral microbial communities. Mol Oral Microbiol 2010, 25:357-367.

33. Consortium HMP: Structure, function and diversity of the healthy human microbiome. Nature 2012, 486:207-214.

34. Kneist S, Schmidt F, Callaway A, Willershausen B, Rupf S, Wicht M, Thiede B: Diversity of Lactobacillus species in deep carious lesions of primary molars. Eur Arch Paediatr Dent 2010, 11:181-186. 
35. Sheffield VC, Cox DR, Lerman LS, Myers RM: Attachment of a 40-base-pair $\mathrm{G}+$ C-rich sequence (GC-clamp) to genomic DNA fragments by the polymerase chain reaction results in improved detection of single-base changes. Proc Natl Acad Sci USA 1989, 86:232-236.

36. Schloss PD, Westcott SL, Ryabin T, Hall JR, Hartmann M, Hollister EB, Lesniewski RA, Oakley BB, Parks DH, Robinson CJ, Sahl JW, Stres B, Thallinger GG, Van Horn DJ, Weber CF: Introducing mothur: open-source, platform-independent, community-supported software for describing and comparing microbial communities. Appl Environ Microbiol 2009, 75:7537-7541.

37. Yue JC, Clayton MK: A similarity measure based on species proportions. Comm Stat Theor Meth 2005, 34:2123-2131.

38. Legendre P, Legendre L: Canonical Analysis. In Numerical Ecology. Edited by Legendre PLL. Amsterdam: Elsevier Science BV; 1983:575-633.

39. Thioulouse J, Chessel D, Doledec S, Olivier JM: ADE-4: A multivariate analysis and graphical display software. Stat Comput 1997, 7:75-83.

40. Li W, Godzik A: Cd-hit: a fast program for clustering and comparing large sets of protein or nucleotide sequences. Bioinformatics 2006 22:1658-1659.

41. Nawrocki EP, Kolbe DL, Eddy SR: Infernal 1.0: inference of RNA alignments. Bioinformatics 2009, 25:1335-1337.

42. Stamatakis A: RAxML-VI-HPC: maximum likelihood-based phylogenetic analyses with thousands of taxa and mixed models. Bioinformatics 2006, 22:2688-2690.

43. Altschul SF, Gish W, Miller W, Myers EW, Lipman DJ: Basic local alignment search tool. J Mol Biol 1990, 215:403-410.

44. Letunic I, Bork P: Interactive Tree Of Life v2: online annotation and display of phylogenetic trees made easy. Nucleic Acids Res 2011, 39:W475-W478.

45. Tanenbaum DM, Goll J, Murphy S, Kumar P, Zafar N, Thiagarajan M, Madupu R, Davidsen T, Kagan L, Kravitz S, Rusch DB, Yooseph S: The JCVI standard operating procedure for annotating prokaryotic metagenomic shotgun sequencing data. Stand Genomic Sci 2010, 2:229-237.

46. Goll J, Rusch DB, Tanenbaum DM, Thiagarajan M, Li K, Methé BA, Yooseph S: METAREP: JCVI metagenomics reports-an open source tool for highperformance comparative metagenomics. Bioinformatics 2010 26:2631-2632

47. Segata N, Waldron L, Ballarini A, Narasimhan V, Jousson O, Huttenhower C: Metagenomic microbial community profiling using unique clade-specific marker genes. Nat Methods 2012, 9:811-814

48. Aspiras MB, Kazmerzak KM, Kolenbrander PE, McNab R, Hardegen N, Jenkinson HF: Expression of green fluorescent protein in Streptococcus gordonii DL1 and its use as a species-specific marker in coadhesion with Streptococcus oralis 34 in saliva-conditioned biofilms in vitro. Appl Environ Microbiol 2000, 66:4074-4083.

49. Aldsworth TG, MacFarlane TW: A novel in vitro model system to grow films of oral bacteria for the study of human tooth root surface caries. J Appl Microbiol 2001, 91:139-146.

50. Palmer RJ Jr, Wu R, Gordon S, Bloomquist CG, Liljemark WF, Kilian M, Kolenbrander PE: Retrieval of biofilms from the oral cavity. Methods Enzymol 2001, 337:393-403.

51. Sissons $\mathrm{CH}$, Cutress TW, Pearce El: Kinetics and product stoichiometry of ureolysis by human salivary bacteria and artificial mouth plaques. Arch Oral Biol 1985, 30:781-790.

52. Sissons C, Wong L, Shu M: Growth of microcosm dental plaque biofilms: Effect of nutrient variation. J Dent Res 1997, 76:1701-1701.

53. Sissons $\mathrm{CH}$, Wong $\mathrm{L}$, Hancock EM, Cutress TW: The $\mathrm{pH}$ response to urea and the effect of liquid flow in 'artificial mouth' microcosm plaques. Arch Oral Biol 1994, 39:497-505.

54. Sissons $\mathrm{CH}$, Wong $\mathrm{L}$, Shu M: Factors affecting the resting $\mathrm{pH}$ of in vitro human microcosm dental plaque and Streptococcus mutans biofilms. Arch Oral Biol 1994, 39:507-511

55. Chestnutt IG, MacFarlane TW, Stephen KW: An in vitro investigation of the cariogenic potential of oral streptococci. Arch Oral Biol 1994, 39:589-593.

56. Whittaker CJ, Klier CM, Kolenbrander PE: Mechanisms of adhesion by oral bacteria. Annu Rev Microbiol 1996, 50:513-552.

57. Yao ES, Lamont RJ, Leu SP, Weinberg A: Interbacterial binding among strains of pathogenic and commensal oral bacterial species. Oral Microbiol Immunol 1996, 11:35-41.

58. McLean JS, Lombardo MJ, Ziegler M, Novotny M, Yee-Greenbaum J, Badge $\mathrm{JH}$, Tesler G, Nurk S, Lesin V, Brami D, Hall AP, Edlund A, Allen LZ, Durkin S, Reed S, Torriani F, Pevzner PA, Friedman R, Venter JC, Lasken RS: Genome of the pathogen Porphyromonas gingivalis recovered from a biofilm in a hospital sink using a high-throughput single cell genomic platform. Gen Res 2013, 23:867-877.

59. McLean JS, Ona ON, Majors PD: Correlated biofilm imaging, transport and metabolism measurements via combined nuclear magnetic resonance and confocal microscopy. ISME J 2008, 2:121-131.

60. Stephan RM, MILLER BF: A quantitative method for evaluating physica and chemical agents which modify production of acids in bacterial plaques on human teeth. J Dent Res 1943, 22:1-6.

61. Kleinberg I, Craw D, Komiyama K: Effect of salivary supernatant on the glycolytic activity of the bacteria in salivary sediment. Arch Oral Biol 1973, 18:787-798.

62. Lazarevic V, Whiteson K, Huse S, Hernandez D, Farinelli L, Osterås M, Schrenzel J, François P: Metagenomic study of the oral microbiota by Illumina high-throughput sequencing. J Microbiol Methods 2009, 79:266-271.

63. Nasidze I, Li J, Quinque D, Tang K, Stoneking M: Global diversity in the human salivary microbiome. Genome Res 2009, 19:636-643.

64. Simsek AD, Sezer S, Ozdemir NF, Mehmet H: Streptococcus vestibularis bacteremia following dental extraction in a patient on long-term hemodialysis: a case report. NDT Plus 2008, 1:276-277.

65. Willcox MD, Knox KW, Green RM, Drucker DB: An examination of strains of the bacterium Streptococcus vestibularis for relative cariogenicity in gnotobiotic rats and adhesion in vitro. Arch Oral Biol 1991, 36:327-333.

66. Horton WA, Jacob AE, Green RM, Hillier VF, Drucker DB: The cariogenicity of sucrose, glucose and maize starch in gnotobiotic rats mono-infected with strains of the bacteria Streptococcus mutans, Streptococcus salivarius and Streptococcus milleri. Arch Oral Biol 1985, 30:777-780.

67. Drucker DB, Shakespeare AP, Green RM: The production of dental plaque and caries by the bacterium Streptococcus salivarius in gnotobiotic WAG/RIJ rats. Arch Oral Biol 1984, 29:437-443.

68. Tanzer JM, Kurasz AB, Clive J: Inhibition of ecological emergence of mutans streptococci naturally transmitted between rats and consequent caries inhibition by Streptococcus salivarius TOVE-R infection. Infect Immun 1985, 49:76-83.

69. Tanzer JM, Kurasz AB, Clive J: Competitive displacement of mutans streptococci and inhibition of tooth decay by Streptococcus salivarius TOVE-R. Infect Immun 1985, 48:44-50.

70. Chen YY, Burne RA: Analysis of Streptococcus salivarius urease expression using continuous chemostat culture. FEMS Microbiol Lett 1996, 135:223-229.

71. Whiley RA, Fraser HY, Douglas CW, Hardie JM, Williams AM, Collins MD: Streptococcus parasanguis sp. nov., an atypical viridans Streptococcus from human clinical specimens. FEMS Microbiol Lett 1990, 56:115-121.

72. Kikuchi K, Enari T, Totsuka K, Shimizu K: Comparison of phenotypic characteristics, DNA-DNA hybridization results, and results with a commercial rapid biochemical and enzymatic reaction system for identification of viridans group streptococci. J Clin Microbiol 1995, 33:1215-1222

73. Becker MR, Paster BJ, Leys EJ, Moeschberger ML, Kenyon SG, Galvin JL, Boches SK, Dewhirst FE, Griffen AL: Molecular analysis of bacterial species associated with childhood caries. J Clin Microbiol 2002, 40:1001-1009.

74. Corby PM, Bretz WA, Hart TC, Schork NJ, Wessel J, Lyons-Weiler J, Paster BJ: Heritability of oral microbial species in caries-active and caries-free twins. Twin Res Hum Genet 2007, 10:821-828.

75. Gross EL, Leys EJ, Gasparovich SR, Firestone ND, Schwartzbaum JA, Janies DA, Asnani K, Griffen AL: Bacterial 16S sequence analysis of severe caries in young permanent teeth. J Clin Microbiol 2010, 48:4121-4128.

76. Alaluusua S, Kleemola-Kujala E, Nystrom M, Evalahti M, Gronroos L: Caries in the primary teeth and salivary Streptococcus mutans and lactobacillus levels as indicators of caries in permanent teeth. Pediatr Dent 1987, 9:126-130.

77. Teanpaisan R, Thitasomakul S, Piwat S, Thearmontree A, Pithpornchaiyakul W, Chankanka O: Longitudinal study of the presence of mutans streptococci and lactobacilli in relation to dental caries development in 3-24 month old Thai children. Int Dent J 2007, 57:445-451.

78. van der Hoeven JS, Mikx FH, Plasschaert AJ, Maltha JC: Experimental periodontal disease in rats induced by plaque-forming microorganisms. J Periodontal Res 1975, 10:143-147.

79. Noorda WD, Purdell-Lewis DJ, van Montfort AM, Weerkamp AH: Monobacterial and mixed bacterial plaques of Streptococcus mutans 
and Veillonella alcalescens in an artificial mouth: development, metabolism, and effect on human dental enamel. Caries Res 1988 22:342-347

80. Liu J, Wu C, Huang $I H$, Merritt J, Qi F: Differential response of Streptococcus mutans towards friend and foe in mixed-species cultures. Microbiology 2011, 157:2433-2444.

81. Rogers AH: Studies on fusobacteria associated with periodontal diseases. Aust Dent J 1998, 43:105-109.

82. Han XY, Weinberg JS, Prabhu SS, Hassenbusch SJ, Fuller GN, Tarrand JJ, Kontoyiannis DP: Fusobacterial brain abscess: a review of five cases and an analysis of possible pathogenesis. J Neurosurg 2003, 99:693-700.

83. Castellarin M, Warren RL, Freeman JD, Dreolini L, Krzywinski M, Strauss J, Barnes R, Watson P, Allen-Vercoe E, Moore RA, Holt RA: Fusobacterium nucleatum infection is prevalent in human colorectal carcinoma. Genome Res 2012, 22:299-306.

84. Fredricks DN, Fiedler TL, Marrazzo JM: Molecular identification of bacteria associated with bacterial vaginosis. N Engl J Med 2005, 353:1899-1911.

85. Brinig MM, Lepp PW, Ouverney CC, Armitage GC, Relman DA: Prevalence of bacteria of division TM7 in human subgingival plaque and their association with disease. Appl Environ Microbiol 2003, 69:1687-1694.

86. Rylev M, Bek-Thomsen M, Reinholdt J, Ennibi OK, Kilian M: Microbiological and immunological characteristics of young Moroccan patients with aggressive periodontitis with and without detectable Aggregatibacter actinomycetemcomitans JP2 infection. Mol Oral Microbiol 2011, 26:35-51.

87. Wade W: Unculturable bacteria-the uncharacterized organisms that cause oral infections. J R Soc Med 2002, 95:81-83.

88. Vartoukian SR, Palmer RM, Wade WG: Cultivation of a Synergistetes strain representing a previously uncultivated lineage. Environ Microbiol 2010, 12:916-928.

89. Marsh PD, Moter A, Devine DA: Dental plaque biofilms: communities, conflict and control. Periodontol 2000 2011, 55:16-35.

doi:10.1186/2049-2618-1-25

Cite this article as: Edlund et al: An in vitro biofilm model system maintaining a highly reproducible species and metabolic diversity approaching that of the human oral microbiome. Microbiome 2013 1:25.

\section{Submit your next manuscript to BioMed Central and take full advantage of:}

- Convenient online submission

- Thorough peer review

- No space constraints or color figure charges

- Immediate publication on acceptance

- Inclusion in PubMed, CAS, Scopus and Google Scholar

- Research which is freely available for redistribution 